\title{
When to count? Indices of population size for mountain hares of the north-west Lammermuir Hills, Scotland
}

\author{
G.W. Pettigrew \\ 20 Kings Park, Longniddry, East Lothian EH32 0QL \\ E-mail: pettigrewgraham@gmail.com
}

\begin{abstract}
Surveys with binoculars at two different times of day and in various months of the year, along with camera trap studies of diel activity patterns, were used to inform an appropriate period to count mountain hares (Lepus timidus) on managed red grouse (Lagopus lagopus) moorland of the Lammermuir Hills, south-east Scotland. Factors affecting the numbers of hares counted were time relative to sunrise, the presence of winter coat colour and reproductive behaviour in spring. Counts of hares in March and April starting one hour before dawn were used as an index of population size of the mountain hare over three years of observations on three hill-tops, with densities of 23-33 hares $\mathrm{km}^{-2}$. The number of hares seen was stable or rose slightly over the three years despite a partial cull on one of the hills. In support of suitability of the timing of surveys used, camera trap studies revealed that the period around dawn in March and April was associated with high levels of hare activity.
\end{abstract}

\section{INTRODUCTION}

The mountain hare (Lepus timidus) is a native mammalian relict species of the last ice age in the alpine regions of the Cairngorm mountains of Scotland (Angerbjörn \& Flux, 1995). This habitat differs from the preference for boreal forest in the bulk of its Eurasian range. In the 19th century the mountain hare was introduced as a game animal onto the heather moorland of shooting estates and these transplant populations persist, particularly in the north-east and south-east of Scotland (Flux, 1970; Patton et al., 2010). Even with the killing component associated with sport shooting and population control in these managed environments, the mountain hare can thrive because of the encouragement of young heather (Calluna vulgaris) growth and the elimination of ground predators (Hewson, 1984).

However, the number of mountain hares counted on a non-random sample of heather moorland and alpine sites in north-east Scotland between 1954 and 1998 declined slowly by about $5 \%$ per annum (Watson \& Wilson, 2018). This was attributed to loss of habitat, for example due to reforestation. From 1998 onwards, a much steeper decline in numbers was observed of around $30 \%$ per annum, down to levels less than $1 \%$ of those observed at the start of the study.
Watson \& Wilson (2018) attributed this decline to extensive mountain hare culling by the shooting estates, which was done in the belief that this practice helps to limit the spread of the louping-ill virus (Flavivirus sp.) to red grouse. Mortality in red grouse infected with the louping-ill virus can be as high as $78 \%$ under laboratory conditions (Reid, 1978). The virus is carried by the sheep tick (Ixodes ricinus) and the tick can survive on wildlife hosts such as red deer (Cervus elaphus) and mountain hare (Jones et al., 1997). On moorland with both domestic sheep (Ovis aries) and wildlife, transmission of the virus is therefore complex. Laurenson et al. (2003), found that the prevalence of louping-ill virus in young red grouse fell when mountain hares were culled to low densities. However, several features of the Laurenson study were unusual and other field studies and modeling results have been thoroughly considered by Harrison et al. (2010) and Gilbert (2016) with the conclusion that when red deer and sheep are present as tick hosts, the mountain hare makes little contribution to the prevalence of the disease in the majority of managed moorland. Despite that evaluation of the evidence, extensive culling of mountain hare has persisted. With particular relevance to this paper, louping-ill virus has not been detected in the Lammermuir Hills.

The mountain hare in the U.K. was protected by an EC Habitats directive (Council of the European Union, 1992). This directive required a government to maintain the animal in a "Favourable Conservation Status", a phrase interpreted to mean the future maintenance of population size and range at the levels present at the time of the directive. The findings of Watson \& Wilson (2018) suggest that this directive was not being satisfied, at least in some of the areas that they studied. However, there is little reliable information on mountain hare range and population size on a national scale. Scottish Natural Heritage (SNH) commissioned an evaluation of methods for counting mountain hares. Based on counting in October and November and working on moorlands in Perthshire and the north-east of Scotland, Newey et al. (2018) used the capture-recapture method as a benchmark against which to judge the effectiveness of different methods. They also concluded that counting from one hour after sunset using either spotlight or thermal cameras gave the closest correlation with the capture-recapture benchmark, and that daylight 
counting from one hour after sunrise gave inconsistent count data compared with night-time counts. This work will form the basis for systematic surveys of managed moorland in Scotland (R. Raynor, SNH, pers. comm.).

The Lammermuir Hills in south-east Scotland (55.8333 ${ }^{\circ}$ $\mathrm{N}, 2.7333^{\circ} \mathrm{W}$ ) is an area largely managed for driven red grouse shooting. In 2014 it was reported that the RSPB had evidence for 1,500-1,700 mountain hares having been killed that year on several shooting estates in the Lammermuir Hills (Edwards, 2014). However, there were no estimates of population size against which to judge the impact of this cull number. Here we report the results of mountain hare counts at three Lammermuir locations around sunrise in spring between 2017 and 2019. In addition, a diel study used camera traps to investigate whether that time of day and time of year were associated with high levels of mountain hare activity.

\section{MATERIALS AND METHODS \\ Counting routes and methods}

We counted on three hills - Meikle Says Law (535 m), Lammer Law (527 m) and Newlands Hill (423 m) - in the north-west Lammermuir Hills. All are in red grouse shooting estates on which the heather moorland is managed by heather-burning and predator control. Mountain hares were counted along the survey routes shown in Fig. 1. The Meikle Says Law route is shown in detail in Fig. 2. The Lammer Law and Newlands hill routes were completed by a single group of observers within $3 \mathrm{~h}$. Due to the length of time required for completing the Meikle Says Law route, counting was conducted by two groups following the solid line and broken line paths to meet at the summit.

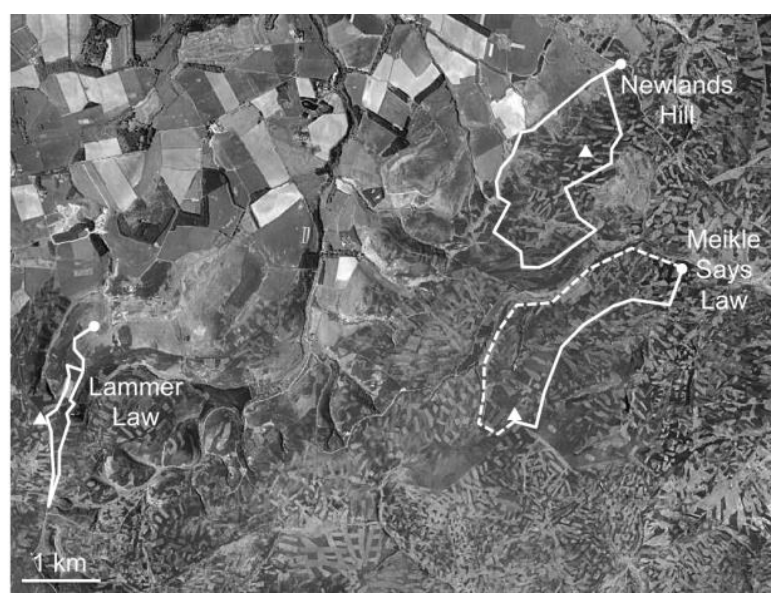

Fig. 1. The north-west Lammermuir Hills, Scotland and the three counting routes. The counting routes are shown as white lines. Due to the length of time required for completing the Meikle Says Law route, we counted in two groups following the solid line and broken line routes to meet at the summit. The white triangles indicate the summit of each hill. The white circles are the start of each transect. (Microsoft product screen shot reprinted with permission from Microsoft Corporation)

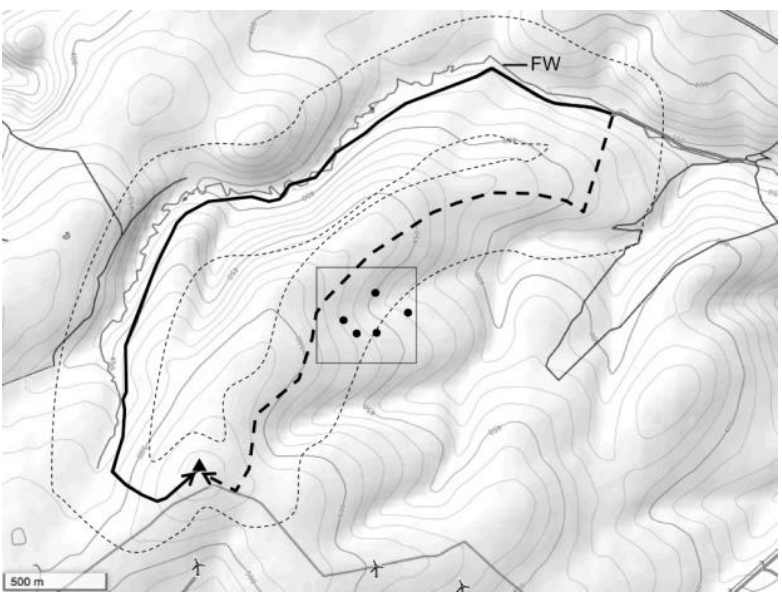

Fig. 2. The Meikle Says Law counting route, north-west Lammermuir Hills, Scotland, which was walked by two teams along two routes (solid and broken lines) between $-1 /+2 \mathrm{~h}$ around sunrise. The area over which mountain hares (Lepus timidus) can be counted with binoculars is indicated by grey broken lines on either side of the routes. The study area for collecting diel activity data is shown as a box of $0.5 \times 0.5 \mathrm{~km}$ containing the positions of five trail cameras as black circles. The black triangle is the summit of Meikle Says Law at $535 \mathrm{~m}$. FW, Faseny Water. The base map is from OpenTopoMap.org. Copyright is held by OpenStreetMap contributors. Copyright conditions are at https://www.openstreetmap.org/copyright.

The counting routes are composed of estate vehicle tracks, some smaller paths and a little rough heather walking. The routes were chosen to encompass broad views on both sides of the path with an emphasis on slopes rising upwards away from the observer. This is especially the case for the route along the valley of the Faseny Water (Fig. 2). The area that could be observed from the counting route was estimated using a map area calculator setting the detection distance with binoculars on either side of the route as either $300 \mathrm{~m}$ or $200 \mathrm{~m}$ depending on the sloping features of the terrain. This should be regarded as a rough estimate of area because of the subtleties in these slopes. The length of the counting route used in the encounter rate calculation was measured using a Garmin GPS device. It should be emphasised that this detection distance for binoculars is heavily dependent on the hares being active, on having their white winter coat, and also on good visibility. Surveys were only conducted in fair, clear, calm weather without snow on the ground. An important aspect of our counting method is that we are observing active hares, not flushing them from cover when they are resting.

Routes were followed consistently between survey dates using a Garmin GPS device. Counting was conducted continuously with small groups of 2-4 surveyors with binoculars. There was corroboration and consultation at a set of fixed stopping point and tight group walking between stopping points. Considerable care was taken to avoid double counting by keeping mental and written records of the location of hares seen and their direction of movement as the route was walked. Each of our counting routes has a region in the centre which is not surveyed. The advantage of this is that it reduces the risk of hare movement away from one survey team then 
leading to counting by the second team (or on the return route in the case of transects that are walked as a single loop). Counting was started approximately $1 \mathrm{~h}$ before sunrise and was completed within $3 \mathrm{~h}$. Mountain hares on each of the three hills were counted twice during the March-April period in each of the three years of the survey.

We are aware that our counting method does not follow the principles of random linear transects. We argue that, for the hill environment, the method we use is an appropriate one to maximise our ability to see hares at a distance. Our routes are followed precisely and repetitively and the review positions along the routes are constant. This is a valid method when our aim is to provide a record of changes in hare numbers at these locations over the years.

The routes were also followed starting $1 \mathrm{~h}$ after sunset and counting by means of a thermal camera (FLIR Scout II 640 thermal imaging camera). The effective range of the thermal equipment used was about $150-200 \mathrm{~m}$.

\section{Activity studies}

Five camera traps (AUCEE Hunting Camera, 12MP 1080P Full HD Infrared Wildlife Camera with Night Vision) were placed on the eastern slopes of Meikle Says Law in positions of known hare activity such as browsing areas and gullies used as hare routes (Fig. 2). Camera traps were triggered by motion either in daylight or at night with a ten second delay between triggers. Time stamps were set to Greenwich Mean Time throughout the year.

For each image that contained a mountain hare an evaluation was made as to whether or not it represented an independent event ("hit"). This involved assessment of the timing, appearance, direction of movement and behaviour of hares in the preceding and following images. Images that were separated by less than one minute were discounted unless image evidence indicated that they were triggered by a different hare. Images separated by more than one minute were not recorded as independent events if image evaluation indicated that they were triggered by the same hare. The time stamps for hits were tabulated in Excel, categorised as morning (before 12:00) and afternoon (12:00 and after) and then re-calculated as decimal time relative to either sunset (afternoon group) or sunrise (morning group). Sunrise or sunset times were taken from data tables at https://www.thetimeandplace.info/uk/ for the local village of Gifford $\left(55.9040^{\circ} \mathrm{N}, 2.7470^{\circ} \mathrm{W}\right)$.

Our surveys are contained within a $3 \mathrm{~h}$ time block starting $1 \mathrm{~h}$ before sunrise and so the camera detections (hits) were further subdivided into the block of $-1 /+2 \mathrm{~h}$ relative to sunrise and those in the remaining $21 \mathrm{~h}$. The hit rate is the number of hits during a month within a 3 h time block.

Statistical analysis was performed in R (R Development Core Team, 2019) to determine whether the hit rate in the $-1 /+2 \mathrm{~h}$ time block differed from that for the remaining $21 \mathrm{~h}$. For each of four independent cameras, the hits for the months of March and April were combined, subdivided into the time blocks of $-1 /+2 h$ and the remaining $21 \mathrm{~h}$. The hit rates were calculated and analysed by the Welch Two Sample t-test (Fig. 3).

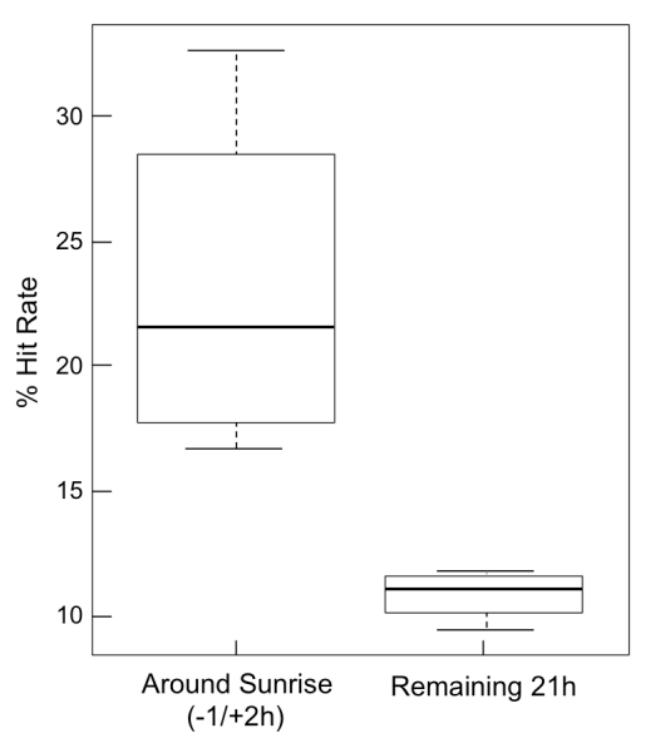

Fig. 3. Box and whisker plots for mountain hare (Lepus timidus) hit rates of $-1 /+2 \mathrm{~h}$ around sunrise and the remaining $21 \mathrm{~h}$. The median percentage hit rate of each day division is shown as a horizontal bar, the box contains the $25-75 \%$ quartiles and the whiskers indicate the highest and lowest values. The "Remaining $21 \mathrm{~h}$ " column represents average percentage $3 \mathrm{~h}$ hit rates for that time block.

Statistical analysis was performed in $\mathrm{R}$ to determine whether the mean percentage frequency of hits in the $1 /+2 \mathrm{~h}$ time block differed from that of the remaining $21 \mathrm{~h}$. For each of four independent cameras, the hits for the months of March and April were combined and subdivided into the time blocks of $1 /+2 \mathrm{~h}$ and the remaining $21 \mathrm{~h}$. Analysis by the Welch Two Sample t-test gave $\mathrm{t}=3.4$, degrees of freedom $=3.1$, and $P$-value $=0.04$. The mean for the time block $-1 /+2 \mathrm{~h}$ around sunrise was $23.17 \%$ and the mean for the remaining $21 \mathrm{~h}$ was $10.98 \%$.

\section{RESULTS}

Optimum time of year and time of day for counting The data from Meikle Says Law obtained during 2015-2016 indicate that the maximum count of mountain hare via walked surveys with binoculars occurred in spring (March and April), with a higher count obtained when counting started $1 \mathrm{~h}$ before sunrise rather than $1 \mathrm{~h}$ after (Fig. 4).

\section{Counting results for three hills over three years (2017-2019)}

The mean number of mountain hare counted increased over the three years at Lammer Law and Newlands Hill (Fig. 5). For Meikle Says Law a similar trend was broken in September 2018 by a cull of 35 hares, which was associated with a lower number of hares in the 2019 counts (Fig. 5). 


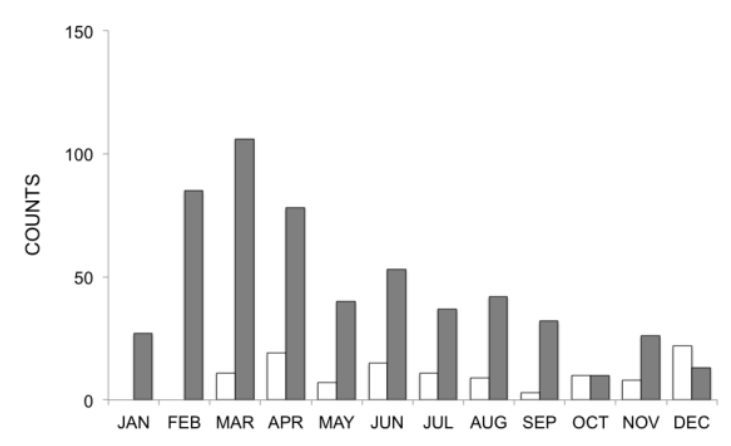

Fig. 4. Mountain hare (Lepus timidus) counts on Meikle Says Law, north-west Lammermuir Hills, Scotland. Effect of time of year and time of day. Clear bars show single counts starting $1 \mathrm{~h}$ after sunrise (2015). Grey bars show single counts starting $1 \mathrm{~h}$ before sunrise (2016).

Survey results expressed as encounter rate (hares seen per $\mathbf{k m}$ ) and as count density (hares seen per $\mathbf{k m}^{2}$ )

The mean counts for 2019 were converted into a linear encounter rate and a count density in Table 1 . The results of Table 1 show that Meikle Says Law is associated with the highest hare counts, but, when transect distance (encounter rate) or transect area (count density) is taken into account, all three hills are similar with values for count density of 23-33 hares per $\mathrm{km}^{2}$.

\section{Activity studies}

The different patterns of hare activity captured by the camera traps in October and March are shown in Fig. 6. This is part of a larger data set, the whole of which is considered in a separate article dealing with changing annual diel patterns (Pettigrew, submitted). We focus on the activity in March (and April) here because the hare counts of Fig. 5 are obtained in March and April. October is chosen as the comparator month because it has a similar pattern of daylight/night hours (Fig. 6A) and also because the assessment of counting methods by Newey et al. (2018) was performed during October and November.

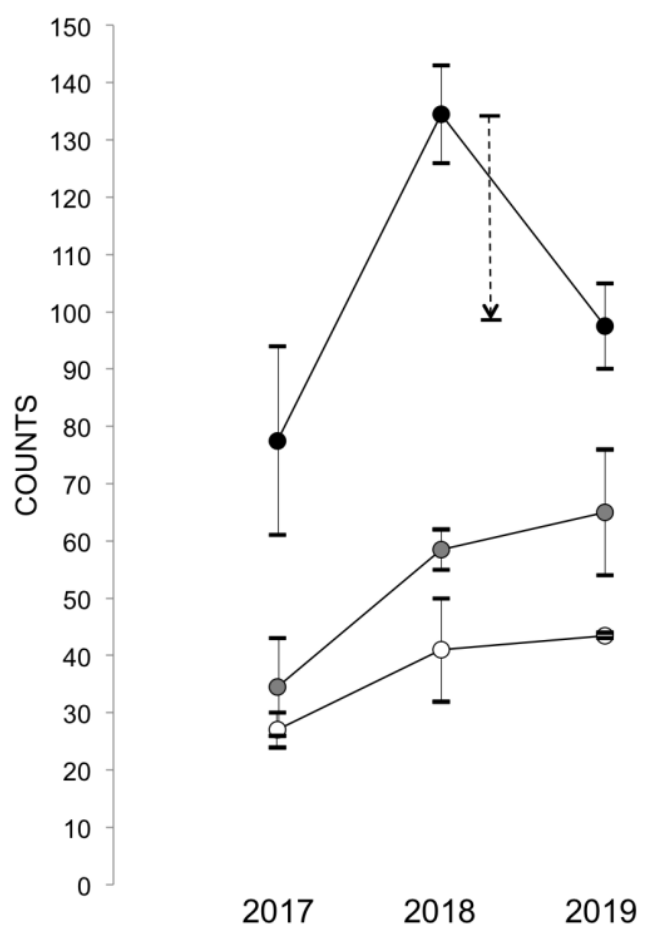

Fig. 5. Trends in annual counts of mountain hares (Lepus timidus), north-west Lammermuir Hills, Scotland. For the three years 2017-2019, the counts for Meikle Says Law are shown as black circles, Newlands Hill as grey circles and Lammer Law as open circles. The circles are the mean of the March and April counts and the limits of the bars are the two individual counts. The broken arrow for Meikle Says Law represents a cull of 35 hares carried out by the estate in September 2018.

\begin{tabular}{lccccccc}
\hline & \multicolumn{9}{c}{ Moorland } & \multicolumn{2}{c}{ Alpine } \\
\hline & MSL & LL & NH & $\begin{array}{c}\text { ML } \\
\text { (pre 1996) }\end{array}$ & $\begin{array}{c}\text { ML } \\
\text { (post 1996) }\end{array}$ & $\begin{array}{c}\text { Cairnwell } \\
\text { (pre 1988) }\end{array}$ & $\begin{array}{c}\text { Cairnwell } \\
\text { (post 1988) }\end{array}$ \\
\hline Count & 98 & 44 & 65 & & & \\
Transect length (km) & 7.6 & 4.5 & 6.9 & & & \\
Transect area $\left(\mathbf{k m}^{\mathbf{2}}\right)$ & 4.17 & 1.32 & 2.5 & & & \\
$\begin{array}{l}\text { Encounter rate } \\
\text { (hares per km) }\end{array}$ & 12.9 & 9.8 & 9.4 & & & \\
$\begin{array}{l}\text { Density } \\
\left(\text { hares per } \mathbf{~ k m}^{2} \text { ) }\right.\end{array}$ & 23 & 33 & 26 & 33.8 & 2.0 & & \\
\hline
\end{tabular}

Table 1. Density and encounter rates of mountain hares (Lepus timidus) on three hills in the north-west Lammermuir Hills, Scotland. The counts shown are the average between the April and the March count in 2019 from the data in Fig. 5. The transect area was estimated using a map area calculator setting the identification distance on either side of the route as either $300 \mathrm{~m}$ or $200 \mathrm{~m}$ depending on the terrain. The densities for Morven Lodge (ML) and Cairnwell are from Watson (2013.) MSL, Meikle Says Law; LL, Lammer Law; NH, Newlands Hill. 

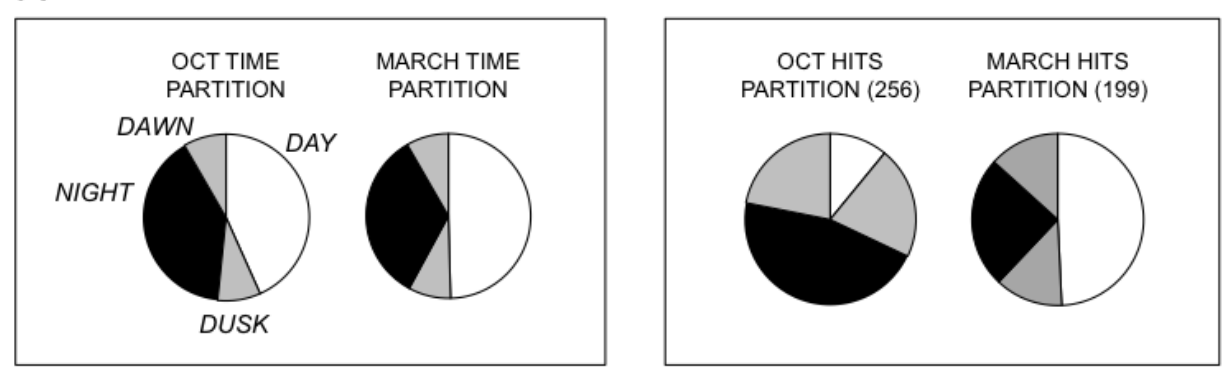

B

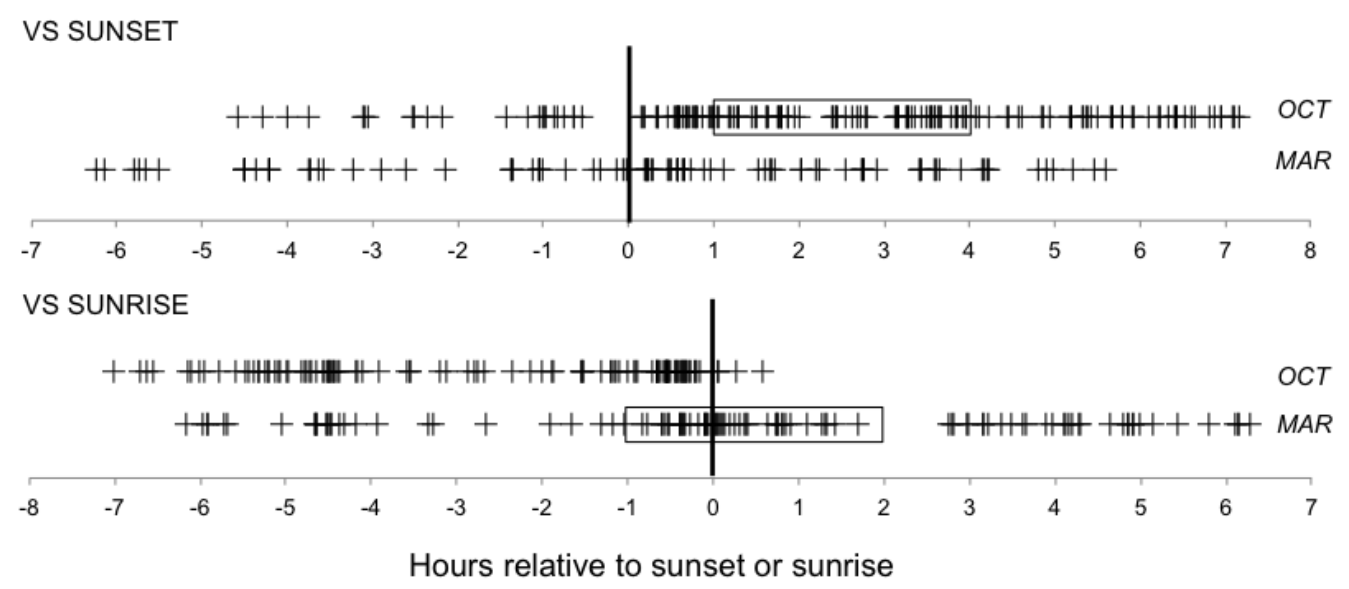

Fig. 6. Measurement of mountain hare (Lepus timidus) activity using camera traps for the months of October (2018) and March (2019). This is part of a larger data set considered in a separate article (Pettigrew, submitted). (A) In the time charts, the sectors represent the mean daylight hours (white), the mean night hours (black) and the $2 \mathrm{~h}$ each for dusk and dawn (grey). In the hits charts, the sectors represent the same day divisions but their size represents the number of hits on five cameras in that day division for that month with the total hits shown in each title. (B) Hits recorded by the camera traps were calculated as Greenwich Mean Time in decimal hours relative to sunset (top graph) or relative to sunrise (bottom graph) depending on whether they occurred in the second half of the day or the first half. The vertical bars represent sunset and sunrise. In each graph the top line of crosses shows the hit times for October and the bottom row of crosses the hit times for March. The boxes represent the time periods used for counting hares in this paper (March, $-1 /+2 \mathrm{~h}$ versus sunrise) and in the planned national census (October, $+1 /+4 \mathrm{~h}$ versus sunset).

In contrast to the time partition, the partition of camera hits between daylight and night is very different between the two months of October and March (Fig. 6A). October is associated with a much lower proportion of hits in daylight (Fig. 6A) and, in particular, in the daylight period between sunrise and noon (Fig. 6B).

Since surveys start $1 \mathrm{~h}$ before sunrise and take $2-3 \mathrm{~h}$ to complete, the raw data from Fig. 6 have been grouped into hits within this $-1 /+2 \mathrm{~h}$ time block and hits per $3 \mathrm{~h}$ blocks in the remaining $21 \mathrm{~h}$. The latter are expressed as a percentage $3 \mathrm{~h}$ rate. A percentage rate of $12.5 \%$ for a three hour block would be obtained if all eight blocks in the $24 \mathrm{~h}$ cycle contained the same number of hits. The spring period of March and April is associated with percentage hit rates of $23-25 \%$ (Fig. 7A) and these are significantly higher than the rate associated with the remaining $21 \mathrm{~h}$.

It should be noticed, however, that a high percentage rate of hits during the $-1 /+2 \mathrm{~h}$ period around sunrise is not sufficient in itself to justify that period as the time of choice for counting. Since a count takes $2-3 \mathrm{~h}$ to complete, it is important that hares are active during that whole period. As an example, although the $-1 /+2 \mathrm{~h}$ period relative to sunrise in October has a moderately high rate of hits of $16 \%$ (Fig. 7A), that activity is concentrated within the hour of dawn (Fig. 6B) and the second (and third) hour of that period is associated with almost no hare activity. This is in contrast to the $-1 /+2 \mathrm{~h}$ period relative to sunrise in March where the pattern of activity is spread over the three hours (Fig. 6B). Also the peak of activity in August and September in Fig. 7A would appear to offer an alternative counting time of year. However, mountain hares lose their white winter coat at the end of April and become much more difficult to spot even if they are active.

Spotlight counting in the study of Newey et al. (2018) which assessed different counting methods was performed during the period $+1 /+4 \mathrm{~h}$ after sunset in October and November. That timing is associated with high levels of hare activity (Fig. 6B) with 19-24\% of hits (Fig. 7B). 

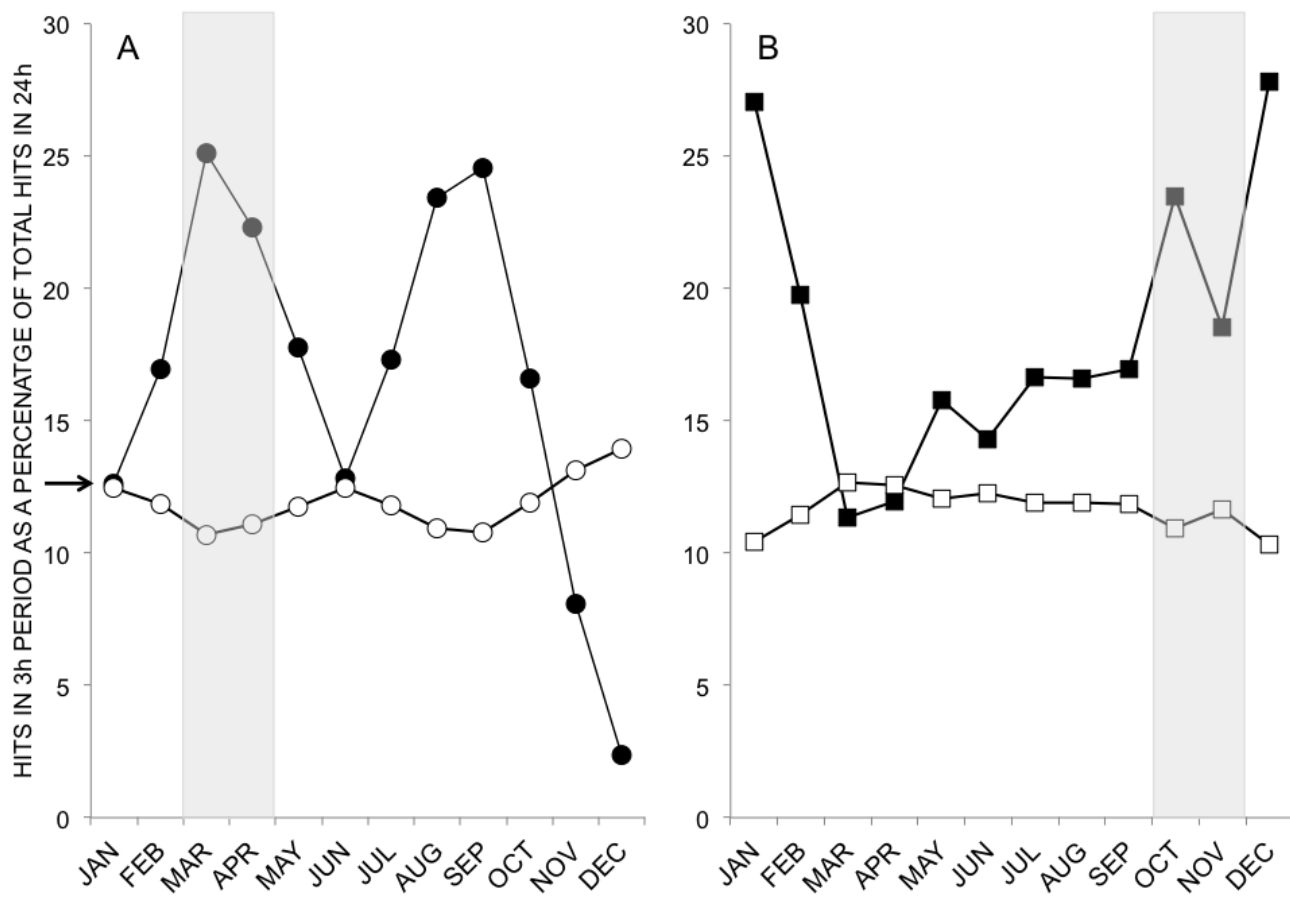

Fig. 7. The rate of mountain hare (Lepus timidus) camera hits in the $3 \mathrm{~h}$ time blocks associated with the counting performed in this paper and with the counting done in Newey et al. (2018). (A) The closed circles represent the percentage rate of camera hits during the $3 \mathrm{~h}$ period $(-1 /+2 \mathrm{~h})$ around sunrise which is the survey period used in this paper. The open circles represent the average percentage 3 $\mathrm{h}$ rates for the remaining $21 \mathrm{~h}$ of the day. The arrow on the vertical axis represents the $12.5 \%$ per $3 \mathrm{~h}$ if all eight $3 \mathrm{~h}$ blocks in one day had the same rate of hits. The grey shaded area shows the two months used for counting in this paper. (B) The closed squares represent the rate of camera hits during the $3 \mathrm{~h}$ period of $+1 /+4 \mathrm{~h}$ after sunset. The open squares represent the average $3 \mathrm{~h}$ rates for the remaining $21 \mathrm{~h}$ of the day. The grey shaded area shows the two months used for counting in the study of Newey et al. (2018).

\section{DISCUSSION}

\section{Counting method}

The decision made to count mountain hare in March and April was based on their higher visibility at that time of year. During these months, their white winter coat (moulted towards the end of April in the Lammermuir Hills) is viewed against a non-white habitat (when clear of snow). Mountain hares are also more active (and therefore visible) in daylight hours than at other times of year (Angerbjörn \& Flux, 1995). Our non-disturbance counting method with broad views of the habitat can give a less intrusive index of population size than a method which involves walking strict lines and flushing hares. Watson (2013) counted in early morning in spring with binoculars in the absence of snow cover and found that there was little or no difference between binocular counts and those performed by pointer dogs. He therefore considered that he was close to estimating total population size for his transects. Our methodology is similar to his.

In an assessment of counting methods, Newey et al. (2018) concluded that daylight counting was unreliable compared with the other methods. However, the daylight counting done by Newey et al. was conducted in October/November and started $1 \mathrm{~h}$ after sunrise, a timing that corresponds to low count numbers in this study (Fig. 4) and also corresponds to zero hare activity in our the camera trap hare activity study (Fig. 6B). Counting at this time gave a mean encounter rate of one hare per km (Newey et al., 2018) (in contrast to 7.85 hares per $\mathrm{km}$ for counting with a thermal camera $1 \mathrm{~h}$ after sunset over the same areas). Almost all hares counted by Newey et al. (2018) during daylight counting were flushed from cover by human proximity.

The data presented here show that a very different situation applies during spring when counting started before sunrise. The activity studies with camera traps show that the period of $-1 /+2 \mathrm{~h}$ around sunrise coincides with high hare activity. The encounter rates (Table 1) are around ten hares per $\mathrm{km}$ on all three hills, at least as high as those counts obtained by Newey et al. (2018) using spotlight or thermal methods at night. The work described here indicates that daylight counting in spring (particularly if started in the dawn period) is a useful way to survey the mountain hare that may be less disruptive of the environment (and the hares themselves with their sensitive night vision) than a night-time method such as straight line walking with a spotlight.

Our activity profile for the hares in October and November shows a cluster of hits in the period of $+1 /+4 \mathrm{~h}$ after sunset (Fig. 6B) with a hit rate of $19-24 \%$ (Fig. 7B). These results support the choice of survey 
timing during the night in October used by Newey et al. (2018).

Newey et al. (2018) found both spotlight and thermal camera surveys gave acceptable correlation with their benchmark method of capture/recapture. In our study, a thermal camera was used to perform spring and autumn counts starting at $1 \mathrm{~h}$ after sunset. This method yielded counts that were about half those obtained in sunrise counting in spring with binoculars. The range of our thermal camera may be as low as $150 \mathrm{~m}$ for reliable identification, roughly half the range of binoculars. Allowing for this, the thermal camera surveys in either spring or autumn yield count densities that are similar to those obtained around sunrise in spring using binoculars.

However, the thermal camera can be associated with difficulties in species identification. In one of our survey areas, Newlands hill, the ranges of brown hare (Lepus europaeus) and mountain hare overlap and the two cannot be reliably distinguished using the thermal camera. All of our transects contain rabbits (Oryctolagus cuniculus) which, although smaller and with a different running style, can also present species identification problems at a distance with the thermal camera.

Thus counting by thermal camera after dusk does not afford additional benefit compared with counting with binoculars in spring during and immediately after the dawn period.

Of the mountain hare survey methods tested by Newey et al. (2018), none, apart from the capture-recapture method, and the Distance sampling included in the Appendix of the report, enable calculation of a total population size. Therefore these methods, along with the method used in this paper should be seen as uncalibrated indices of population size, year-on-year.

There are two further considerations regarding counting methodologies for the mountain hare when applied on a national scale. Firstly, in the public perception, it may be preferable to have a counting procedure that is seen to be independent of the shooting estates - current plans for surveys of managed moorland involve the participation of gamekeepers (R. Raynor, SNH, pers. comm.). Secondly, compared with dawn counting with binoculars, the aspects of night walking on moorland is more challenging for volunteer groups and the cost of the equipment can be prohibitive.

\section{Mountain hare counts}

Our counts in three successive years on three hills in the Lammermuir Hills are consistent with generally stable and substantial populations. This is so even in the case of Meikle Says Law, where a limited cull took place in 2018. We were supplied with that culling information based on a relationship of trust between the Mayshiel Estate and the Lammermuir Hare Group. Having culling information will be an important component in judging the stability of the Lammermuir hare populations using future counts over the coming years.

Our count densities (Table 1) are broadly in the same range as those found in the Scottish highland areas of Morven Lodge (moorland) and the Cairnwell (alpine) by Watson (Watson, 2013; Watson \& Wilson, 2018). The count densities reported in this paper will be subject to greater error because our calculation of surveyed area based on "reach" of binoculars has intrinsic imprecision compared with straight line counts. The results of Watson \& Wilson (2018) for Morven Lodge show the striking decline in the population density index after 1996 that Watson found in other moorlands of north-east Scotland. As noted above, Watson \& Wilson (2018) attribute these declines to mountain hare culling by estates, which is done in the belief that removal of mountain hares will limit the spread of the louping-ill virus.

The conservation of mountain hares is often portrayed as a simple issue of prevention of culling. In Sweden, the average winter survival for adult hares was $42 \%$ at low predation pressure but $19 \%$ at high predation (Angerbjörn \& Flux, 1995). Therefore the annual morbidity on managed red grouse moors may be about half that in unmanaged habitats, and the main contributory factor to that is likely to be the control of ground and probably avian predators (although habitat management such as muirburn will contribute). As a consequence, in Scotland, mountain hare populations in such managed environments can increase to densities that can be as high as 245 hares $\mathrm{km}^{-2}$ whereas on unmanaged moorland, the numbers can be as low as 0.5$3 \mathrm{~km}^{-2}$ (Watson \& Hewson, 1973).

With such high densities, culling is seen by the shooting estates as part of land management (a topic evaluated by Brooker et al. (2018)) with managers arguing that dense hare populations encourage the spread of disease. Relevant to that argument is the evidence of Newey \& Thirgood (2004) who found high nematode burdens in Scottish mountain hares. When the females were treated with anthelmintics, they showed increased fecundity. One might speculate that a high nematode burden in a dense population could therefore lead to a population decline and that, in such circumstances, carefully managed culling might limit overpopulation and the spread of the parasites. However, evidence is needed for the effect of overpopulation on the spread of disease in mountain hares before culling can be justified.

One might argue that there are two distinct populations of mountain hares in Scotland that could be subject to different conservation criteria. Because the relict population on the high alpine habitats of the Central Highlands is the true native population, this could be regarded as the key conservation target and should receive priority. On the other hand, carefully licensed culling may be appropriate for dense populations that originate as transplants onto managed red grouse moors. 


\section{ACKNOWLEDGEMENTS}

I would like to thank the three head keepers on the three survey Estates - Phil Savage (Mayshiel Estate), Ian Elliot (Hopes Estate) and John Fraser (Snawdon Estate) for their permission to survey and their helpful assistance. Robbie Douglas Miller (the owner of the Hopes Estate) coordinated regular meetings.

The Lammermuir Hare Group is composed of volunteers interested in the mountain hare. There are about 40 individuals in the larger group including visiting students from University courses.

I thank Colin Ballantyne, Angus Currie, Sarah Chambers, Dave Habgood, John Hardy, Joyce Kent, Graeme MacGregor, Maxine Pettigrew, Duncan Priddle, Gordon Steele and Peter Wells for invaluable help in performing the bulk of the survey work. Occasional help with the survey work was provided by students from Edinburgh Napier University and the University of Edinburgh.

The statistics in $\mathrm{R}$ were done under the guidance of Valentina Di Vita. Valentina Di Vita and Jason Gilchrist greatly improved the manuscript with helpful comments.

The camera traps and the thermal camera were purchased with generous funding by the People's Trust for Endangered species.

\section{REFERENCES}

Angerbjörn, A. \& Flux, J.E.C. (1995). Lepus timidus. Mammalian Species 495, 1-11. https://doi.org/10.2307/3504302

Council of the European Union (1992). Council Directive 92/43/EEC of 21 May 1992 on the Conservation of Natural Habitats and of Wild Fauna and Flora.

Brooker, R., Hester, A., Newey, S. \& Pakeman, R. (2018). Socio-economic and Biodiversity Impacts of Driven Grouse Moors in Scotland. Part 2: Biodiversity Impacts of Driven Grouse Shooting in Scotland.

https://sefari.scot/research/socioeconomic-and-biod iversity-impacts-of-driven-grouse-moors-in-scotlan d

Edwards, R. (2014). Outrage over mountain hare 'massacre'. The Herald, 28th September.

Flux, J.E.C. (1970). Life history of the Mountain hare (Lepus timidus scoticus) in north-east Scotland. Journal of Zoology 161, 75-123. https://doi.org/10.1111/j.1469-7998.1970.tb02171.x

Gilbert, L. (2016). Louping-ill virus in the UK: a review of the hosts, transmission and ecological consequences of control. Experimental and Applied Acarology 68, 363-374. https://doi.org/10.1007/s10493-015-9952-X

Harrison, A., Newey, S., Gilbert, L., Haydon, D.T. \& Thirgood, S.J. (2010). Culling wildlife hosts to control disease: mountain hares, red grouse and louping-ill virus. Journal of Applied Ecology 47, 926-930. https://doi.org/10.1111/j.1365-2664.2010.01834.x

Hewson, R. (1984). Mountain hare Lepus timidus bags and moor management. Journal of Zoology 204, 563-565.

https://doi.org/10.1111/j.1469-7998.1984.tb02388.x

Jones, L., Gaunt, M., Hails, R., Laurenson, K., Hudson, P.J., Reid, H.W. \& Gould, E. (1997). Amplification of louping-ill virus infection during co-feeding of ticks on mountain hares (Lepus timidus). Medical and Veterinary Entomology 11, 72-176.

https://doi.org/10.1111/j.1365-2915.1997.tb00309.x

Laurenson, M.K., Norman, R.A., Gilbert, L., Reid, H.W. \& Hudson, P.J. (2003). Identifying disease reservoirs in complex systems: mountain hares as reservoirs of ticks and louping-ill virus, pathogens of red grouse. Journal of Animal Ecology 72, 177-185. https://doi.org/10.1046/j.1365-2656.2003.00688.x

Newey, S. \& Thirgood, S. (2004). Parasite-mediated reduction in fecundity of mountain hares. Proceedings of the Royal Society B: Biological Sciences 271 (Suppl. 6), S413-S415. https://doi.org/10.1098/rsbl.2004.0202

Newey, S., Fletcher, K., Potts, J. \& Iason, G. (2018). Developing a counting methodology for mountain hares (Lepus timidus) in Scotland. Scottish Natural Heritage Research Report No. 1022.

Patton, V., Ewald, J.A., Smith, A.A., Newey, S., Iason, G.R., Thirgood, S.J. \& Raynor, R. (2010). Distribution of mountain hares Lepus timidus in Scotland: results from a questionnaire. Mammal Review 40, 313-326. https://doi.org/10.1111/j.1365-2907.2010.00162.x

R Development Core Team (2019). $R$ - A Language and Environment for Statistical Computing. $\mathrm{R}$ Foundation for Statistical Computing, Vienna, Austria.

Reid, H.W. (1978). The epidemiology of louping-ill. In: Wild, J.K.H. (Editor). Tick-borne Diseases and their Vectors, pp. 501-507. Edinburgh University Press, Edinburgh.

Watson, A. (2013). Mammals of the Northeast Highlands. Paragon Publishing, Bath.

Watson, A. \& Hewson, R. (1973). Population densities of mountain hares (Lepus timidus) on western Scottish and Irish moors and Scottish hills. Journal of Zoology 170,151-159. https://doi.org/10.1111/j.1469-7998.1973.tb01371.x

Watson, A. \& Wilson, J.D. (2018). Seven decades of mountain hare counts show severe declines where high-yield recreational game bird hunting is practiced. Journal of Applied Ecology 55, 26632672. https://doi.org/10.1111/1365-2664.13235 